\title{
Somatoform dissociation among Swedish adolescents and young adults: The psychometric properties of the Swedish versions of the SDQ-20 and SDQ-5
}

Doris Nilsson, Annika Lejoonclou, Mattias Jonsson, Carl Göran Svedin and Rolf Holmqvist

\author{
Linköping University Post Print
}

\section{Tweet}

N.B.: When citing this work, cite the original article.

Original Publication:

Doris Nilsson, Annika Lejoonclou, Mattias Jonsson, Carl Göran Svedin and Rolf Holmqvist, Somatoform dissociation among Swedish adolescents and young adults: The psychometric properties of the Swedish versions of the SDQ-20 and SDQ-5, 2015, Nordic Journal of Psychiatry, (69), 2, 152-160.

http://dx.doi.org/10.3109/08039488.2014.949851

Copyright: Informa Healthcare http://informahealthcare.com/

Postprint available at: Linköping University Electronic Press http://urn.kb.se/resolve?urn=urn:nbn:se:liu:diva-110440 
Somatoform dissociation among Swedish adolescents and young adults: The psychometric properties of the Swedish versions of the SDQ-20 and SDQ-5.

Doris Nilsson $\mathrm{PhD}^{1 *}$ Annika Lejonclou, $\mathrm{MA}^{1}$, Carl Göran Svedin MD PhD ${ }^{2}$, Mattias Jonsson, $\mathrm{MA}^{1} \&$ Rolf Holmqvist $\mathrm{PhD}^{1}$.

${ }^{1}$ Department for Behavioral Sciences and Learning

Section for Clinical Psychology, Linköping University,

SE-581 83 Linköping, Sweden

${ }^{2}$ Child and Adolescent Psychiatry, Department of Clinical and

Experimental Medicine, Faculty of Health Sciences, Linköping University,

SE-581 85 Linköping, Sweden

Corresponding author:

* Doris Nilsson, Department for Behavioral Sciences and Learning

Section Clinical Psychology, Linköping University

58185 Linköping, Sweden

Tel: +461328100

E-Mail doris.nilsson@liu.se

Running head: Somatoform dissociation among adolescents, SDQ-20, psychometrics 
Somatoform dissociation among Swedish adolescents and young adults: The psychometric properties of the Swedish versions of the SDQ-20 and SDQ-5. 
Abstract

Background: Somatoform dissociation is supposed to be a vital aspect of the general concept of dissociation. The Somatoform Dissociation Questionnaire-20 (SDQ-20) and the brief version SDQ-5 are self-report instruments constructed to identify somatic dissociation. Aim: In the present study, the psychometric qualities of the Swedish version of the SDQ-20 and its brief version, the SDQ-5, were examined among adolescents and young adults. Reliability and concurrent validity were investigated. Methods: A total of 512 adolescents and young adults participated in the study: 461 adolescents from a nonclinical sample and 50 adolescents and young adults from a clinical eating disorder outpatient unit. They completed the self-report instruments the SDQ-20, the SDQ-5 (part of SDQ-20), the Linköping Youth Life Experience Scale (LYLES; a trauma history scale) and the Dissociation Questionnaire-Sweden (Dis-QSweden). Results: Both internal consistency and test-retest reliability of the Swedish version of SDQ-20 were good in both the non-clinical $(\alpha=.83)$ and the clinical groups $(\alpha=.84)$; the reliability for the SDQ-5 was, however, lower (non-clinical $\alpha=.50$, clinical $\alpha=.64$ ). Significant differences were found between the clinical and non-clinical groups on both somatoform and psychoform dissociation. Correlations between the Dis-Q-Sweden, SDQ-20, and SDQ-5 were generally high. The criterion and convergent validity was acceptable for both scales but somewhat better for SDQ-20 than for SDQ-5. Conclusion: The advantage with both the SDQ-20 and the SDQ-5 is that they are short questionnaires, but the results suggests that SDQ-20 is preferable based on the higher-quality psychometric properties of the SDQ-20.

Keywords: Somatoform dissociation, SDQ-20, adolescents, psychometrics, self-assessment 


\section{Background}

In the early 1990s, Putnam (1) wrote, 'Dissociation is a psycho-physiological process that alters a person's thoughts, feelings, or actions so for a period of time certain information is not associated or integrated with the information as it normally or logically is' (p. 40). In this definition of dissociation, there is also an indication of the importance of the body. The notion that dissociation is a psycho-physiological process thus also considers bodily dissociation. In the current research literature, there are descriptions of both what is called psychoform dissociation and somatoform dissociation (2). Psychoform dissociation encompasses the symptom clusters dissociative amnesia, depersonalisation, derealisation, identity confusion/identity fragmentation and identity alteration (3). Psychoform dissociation refers to the separation or mal-integration of mental content that under normal circumstances would be integrated or processed together (3). Somatoform dissociation refers to physical symptoms, signifying a general medical condition that appears upon reactivation of dissociative states (45). Somatoform dissociation is manifested as a loss of the normal integration of bodily components such as disturbances of sensation, movement, and other bodily functions. Nijenhuis et al. (6-7) argue that it is necessary not only to think of dissociation as a mental process, but also to take into consideration the bodily expressions of dissociation. According to Nijenhuis et al. (6-7), it is important to give attention to the somatic expressions of dissociation such as loss of bodily feelings, and disturbances in seeing, hearing, perception, and moving. The clinical relevance of attending to bodily expressions of dissociation has been shown in several papers (8-11). Furthermore, in the International Classification of Diseases 
(ICD-10) (12), the various expressions of conversion disorder-such as medically unexplained motor weakness, loss of other sensory functions such as touch, sight, and hearing, and non-epileptic seizures — are categorised under the heading of dissociative disorders. However in DSM-IV (13) and in the recently published DSM-5 (14), conversion disorder is categorised under the heading Somatic disorder.

Nijenhuis, together with colleagues (6), developed the Somatoform Dissociation Questionnaire (SDQ-20) for the purpose of identifying the bodily expressions of dissociation. The SDQ-20 identifies forms of dissociation other than those identified by scales measuring psychoform dissociation such as the Dissociation Experience Scale (15) and the Dissociation Questionnaire (16). Nijenhuis et al. (6-7) showed that the SDQ-20 has satisfactory psychometric characteristics such as good internal consistency $(\alpha=.95)$ and convergent validity, as the scale correlated significantly with the Dis-Q. The SDQ-20 has been translated into several languages and the psychometric characteristics have been tested and found to be satisfactory (17-20). Nijenhuis et al. (21) also developed a short version of the SDQ-20 called the SDQ-5, and suggested that it could be used as a brief screening instrument (21).

Several studies have found correlations between potentially traumatic experiences and dissociative symptoms $(7,16,22-29)$. Some studies also indicate that dissociative symptoms are inflicted to a greater extent by the cumulative effects of traumas (polytraumatisation) than by a single trauma (30-31), and also that interpersonal traumas generate more dissociative symptoms than non-interpersonal traumas (22,30, 32-34). In another study, Maaranen et al. (35) investigated the link between psychoform dissociation and somatoform dissociation, and found that high levels of both psychoform and somatoform dissociative symptoms had strong co-morbidity with depressive symptoms and suicidal tendencies. These findings suggest that 
somatoform dissociation may be associated with pathology, but more studies need to be done. A particularly interesting group is patients with eating disorders since many studies have found that dissociative symptoms are more common in individuals with eating disorders (3638). A substantial number of persons with eating disorders (20-50\%) have been found to have both dissociative symptoms and a background of traumatic experiences $(16,38-40)$. Few studies report on demographic characteristics such as gender or age differences and Nijenhuis (41) concludes that no indication of gender and age differences has been found. However Maaranen (23) reported a higher mean on the SDQ-20 for males in the general population.

\section{Aim}

The objective of this study was to investigate reliability and concurrent (convergent and criteria-related) validity of the Swedish versions of the SDQ-20 and the SDQ-5. We hypothesised that both the SDQ-20 and the SDQ-5 would correlate significantly with the DisQ-Sweden, and that the more potentially traumatic events the participants reported, the more somatic dissociative symptoms they would report. Based on earlier studies, we chose young women with eating disorder as a clinical group hypothesising that there would be significantly more self-reported symptoms of both psychoform and somatoform dissociation in this group compared to a non-clinical group.

\section{Methods}

Participants and procedures 


\section{The non-clinical group}

The headmasters of 15 different schools in two cities were contacted by e-mail, and after approving the study, supplied contact with a teacher. Two schools (one in each city) did not approve participation because of a lack of time. Written information was given to pupils and parents. After informed consent was obtained, one researcher went to the class and administered the questionnaires. All questionnaires were answered anonymously. The data collection was based on self-rating instruments and the researcher was available during the completion of the instruments to answer questions. The researcher also explained practical issues and briefly defined some of the central concepts in the instruments. All questions were handled immediately. Those who wanted help or felt upset while answering the questionnaires were offered counselling afterwards. None of the participants took up the offer.

A total of 568 adolescents from 27 classes were informed about the study. The participants were recruited from secondary schools (34.9\%) and high schools $(65.1 \%)$ in two different cities in the south of Sweden. There was a uniform distribution between classes of theoretical and practical school programs as well as between male and female participants. Of those who were informed, 461 adolescents completed the questionnaires. The participation rate was $81.2 \%$. On the test day, $106(18.7 \%)$ of the pupils were not present in the classes. One pupil refused to participate in the study. This school absence figure is somewhat higher than normal for Swedish schools, where the absence is around $10 \%$ according to the national office Statistic Sweden. The respondents were $53.2 \%$ female, and the mean age was 16.7 years ( $\mathrm{SD}=1.1$, range 15-20). The participants completed the SDQ-20 (including the SDQ5), the Dissociation Questionnaire-Sweden (Dis-Q-Sweden), and the Linköping Youth Life Experience Scale (LYLES). The SDQ-5 was not distributed separately in this study as its 5 
items are included in the SDQ-20. Out of the 461 participants, six persons did not answer all the questions and these questionnaires were excluded in the analyses.

\section{Test-retest group}

Thirty-four students were asked to complete the SDQ-20 a second time, after three weeks. Nineteen of them did return the SDQ-20 a second time (attrition was thus 44\%). The group was chosen as a convenience sample since closeness to the university campus was the most cost-effective way to gather data on two different occasions. Most of these students came from the psychology program, but there were also some students from the engineering program. The mean age in this group was 26.2 years $(\mathrm{SD}=5.7)$.

\section{Clinical group}

A total of 80 young women diagnosed with eating disorders were asked to participate in the study. All were in treatment at an outpatient unit for eating disorders and, after informed consent was obtained, 50 agreed to participate and completed the questionnaires (participation rate $62.5 \%$ ). When participants were less than 18 years of age, the parents were informed and their informed consent was obtained. The mean age in the clinical group was 19.9 years $(\mathrm{SD}=$ 3.4, range 14-30). Among them, 12 were between 14 and 17 years old, 33 were between 18 and 23 years old, and 5 were between 24 and 30 years old. The diagnoses in the clinical group were: Anorexia nervosa $(\mathrm{n}=17)$, Atypical anorexia nervosa $(\mathrm{n}=6)$, Bulimia nervosa $(\mathrm{n}=5)$, Atypical bulimia nervosa $(\mathrm{n}=3)$, Eating disorder, unspecified $(\mathrm{n}=17)$, Overeating associated with other psychological disturbances $(\mathrm{n}=1)$, Other eating disorders $(\mathrm{n}=1)$. The clinical group completed the SDQ-20, the Dis-Q-Sweden, and the LYLES. The reason for choosing an eating disorder group for this study was that previous studies have found high levels of dissociation (16) in eating disorder groups. Causes of attrition included the patients not 
feeling well enough to participate, having left treatment, and in some cases, simply not submitting answers.

\section{Questionnaires}

The Somatoform Dissociation Questionnaire-20 (6) was independently translated into Swedish by three researchers, all experts in the field of psychiatry (42). A consensus version was then back translated and sent to the designer of the test who, after some changes, gave approval to the Swedish version of the SDQ-20. The procedure followed the World Health Organisation's recommendations for translation of psychological tests. The SDQ-20 is a 20item self-report questionnaire where the participant is asked to identify the extent to which each statement is applicable on a 5-point Likert scale. It contains statements like, 'My body or part of it is insensitive to pain' and 'My body, or part of it, feels numb'. For every statement, there is also a question about whether or not any physical reason is known.

The SDQ-20 has been used in studies with clinical groups $(16-17,19)$ and in two studies in the general population in Finland $(22,34)$. The reported Cronbach's alpha in the clinical samples has been $\alpha=.91-.98(6-7,19-20)$, while it has been lower in samples from the general population with $\alpha=.83$ (22). The SDQ-20 has also shown high correlation with the Dis-Q, giving $r=.76, r=.82$, and $r=.73$ for the total scale, and the subscales yielding the following results: identity confusion $r=.73$; loss of control $r=.70$; amnesia $r=.71$; and absorption $r=.46(6-7,20)$. A Swedish pilot study of the SDQ-20 has been performed (42). This pilot study $(n=79)$ showed that the SDQ-20 correlated moderately $(r=.59)$ with the Dissociation Questionnaire-Sweden (20) and with the Symptom Checklist-90 (SCL-90) $(r=$ .62) (44). The internal consistency was $\alpha=.80$ in the Swedish pilot study, and the author concludes that the SDQ-20 may have acceptable convergent and discriminant validity. 
Various cut-off scores $-\geq 30, \geq 35$ and $\geq 40$ - have been used to identify clinically significant somatoform dissociation and for the study of sensitivity and specificity (16). A cut-off score of $\geq 30$ for identifying clinically significant dissociation has been suggested by several researchers $(16,22,45)$ and has been used in this study as well.

The Somatoform Dissociation Questionnaire-5 (SDQ-5) (20) is a brief self-report instrument that was developed out of the SDQ-20 using five of the SDQ-20 questions with the idea that they might screen for somatic dissociation (20). These are the five questions: 1 . I have pain while urinating; 2 . My body, or part of it, is insensitive to pain; 3 . I see things around me differently than usual (for example, as if looking through a tunnel, or seeing merely a part of an object); 4. It is as if my body, or part of it, has disappeared; 5. I cannot speak (or only with great effort) or can only whisper. Nijenhuis et al. (21) found that these five items contributed independently to discriminate between patients with dissociative disorders, patients with non-dissociative disorder, and non-cases. According to Nijenhuis and co-workers (21), the cut-off limit for clinical dissociation is $\geq 8$ (a value of five implies no symptoms at all). Nijenhuis et al. (21) report a Cronbach's alpha of 0.80. There are few studies where the SDQ-5 has been used (19-20). The SDQ-5 was used in Sweden for the first time in a study by Larsson (46). In Larsson's study of 188 non-clinical adolescents aged 17.0 years $(\mathrm{SD}=1.01)$, the internal consistency (Cronbach's alpha) was found to be $\alpha=.47$, and the test-retest reliability was $r=.93(p<.01)$. The mean rating value was $5.64(\mathrm{SD}=1.47)$, which is well below the cut-off point of $\geq 8$ suggested by Nijenhuis et al. (21).

The Linkoping's Youth Life Experience Scale (LYLES) (31) is a trauma history questionnaire. It contains 23 main questions and 18 additional detailed questions, for 41 
questions total. Eighteen items measure non-interpersonal event (nIPE) traumas, 13 items measure interpersonal event (IPE) traumas, and 10 items ask about longstanding adverse childhood circumstances (ACC), such as whether one has been bullied, had parents suffering from alcohol or drug abuse, or had parents in prison (for the whole scale, see previous publications) (31). The LYLES is intended to cover several important areas of potentially traumatic events and circumstances during the lifespan of the adolescent. The test-retest reliability was found to be to be $r=.79(\mathrm{p}<.01)$ for the whole scale, and kappa statistics (Cohen's kappa) item per item ranged between 0.44 and 1.0. In the present study, the answers were counted as $0=$ not experienced, and $1=$ experienced the situation one or more times. Subscale scores were counted by totalling the scores on the subscale items and dividing by the number of items in that scale.

The Dissociation Questionnaire-Sweden (Dis-Q-Sweden) is an instrument for assessment and screening of dissociative symptoms originally developed by Vanderlinden and his colleagues (16) and translated into Swedish. The Dis-Q-Sweden is composed of 63 items on a 5-point Likert scale and the scale contains 4 subscales intended to measure different aspects of dissociation. The subscales are: 1) identity confusion/fragmentation; 2) loss of control; 3) amnesia; and 4) absorption. A total score and the 4 subscale scores are obtained by dividing the raw scores by the number of the included items. The Dis-Q-Sweden is suitable for use with people aged 13/14 and up through adulthood. The instrument has been used in several studies investigating the adolescent population in Sweden (28-31). The Swedish version has shown satisfactory reliability and validity (28-30).

\section{Ethical considerations}


The study was approved by the Human Research Ethics Committee, Faculty of Health Sciences, Linköping University. Written informed consent was given by all participants, and by parents when under the age of 18 , in the clinical group.

\section{Statistical analyses}

Differences between the groups were assessed with t-tests, and correlations between the instruments with Pearson's r. As the distributions of the total scores on the SDQ-20 and the SDQ-5 were heavily skewed (skewness $=2.8$, standard error $=.11, \mathrm{p}<.05$ for SDQ-20, skewness $=3.09, \mathrm{SE}=.11, \mathrm{p}<.05$ for SDQ-5), log transformations of these variables were used in the correlation analyses. The test-retest correlation was analysed as percentages as the floor effect was strong with a large number of returned questionnaires with zero ratings on all items. The scales' psychometric characteristics were analysed with means and variances, and with internal consistency analyses. The importance of the individual LYLES items for the scores on the SDQ-20 and the SDQ-5 was assessed with regression analyses.

\section{Results}

\section{Reliability}

The internal consistency Cronbach's alpha in the non-clinical group was $\alpha=.83$ for the SDQ20 and $\alpha=.50$ for the SDQ-5. No single item reduced the $\alpha$-value more than just marginally on any of the scales. In the clinical group, Cronbach's alpha was $\alpha=.84$ for the SDQ-20 and $\alpha=.64$ for the SDQ-5. The correlation between the SDQ-5 and the SDQ-20 (when the SDQ-5 
items were removed) was $r=.68$. Out of the 19 participants who completed the SDQ-20 twice, $13(68 \%)$ had the same score the second time. Two participants had differences larger than one point (from 26 to 20 and from 22 to 20). On the SDQ-5, 14 (74\%) out of 19 participants scored the same; the difference was not larger than one point for any participant. In Table 1, gender differences in the nonclinical group are shown. As can be seen, there were clearly significant differences between males and females on all scales except SDQ-5, where no significant difference was found. For the SDQ-20, there was a significant difference but not as large as for the Dis-Q scale.

Insert Table 1 about here

\section{Validity}

Table 2 shows the means and standard deviations in the non-clinical and clinical groups, as well as a comparison of only females from the non-clinical group and the clinical eating disorder group for the scales of SDQ-20, SDQ-5, Dis-Q-Sweden, and LYLES. The differences between the means are also presented.

Insert Table 2 about here 
The results presented in Table 2 indicate that there were substantial and significant differences $(\mathrm{p}<.001)$ between the two groups on the dissociation measures (SDQ-20, SDQ-5, and Dis-QSweden), with significantly more symptoms of dissociation in the clinical group. This was also true when only the non-clinical females were compared with the clinical. The differences on the LYLES were comparatively smaller, with non-significant differences concerning interpersonal traumas and fewer experiences of non-interpersonal traumas in the clinical group $(\mathrm{p}<.01)$, while adverse childhood circumstances were more frequent in the clinical group $(\mathrm{p}<.001)$.

The scores on the SDQ-20 were heavily skewed (skewness $=2.78$ ). When differentiated between the groups, it was somewhat smaller in the clinical group (1.41) compared to the non-clinical group (3.1). For the SDQ-5, the skewness was 3.09. For the clinical group, it was 2.02, and for the non-clinical group it was 2.85. Prevalence of high somatoform dissociation (SDQ-20>30) was 9\% in the non-clinical group, and 44\% in the clinical group on the SDQ20. For the SDQ-5, the prevalence of high somatoform dissociation (>8) was $6 \%$ in the nonclinical group and $24 \%$ in the clinical group.

The convergent and discriminant validity were studied by analysing the correlations between the SDQ-20 and the SDQ-5 with the Dis-Q-Sweden and the LYLES. Table 3 shows the correlations with Dis-Q-Sweden. The analyses were made for the clinical and non-clinical groups separately, as well as for the whole sample.

Insert Table 3 about here 
The results in Table 3 show that the correlations between the SDQ-20 and the Dis-QSweden were generally high. The strengths of the correlations were evenly distributed, ranging from strong to moderate between the different subscales of the Dis-Q-Sweden. The correlations with the SDQ-5 were somewhat weaker overall.

\title{
Criterion related validity
}

The correlations between the SDQ-20, the SDQ-5, and the LYLES were low to moderate. The results are shown in Table 4.

\author{
Insert Table 4 about here
}

As the results in Table 4 demonstrate, the correlations between the SDQ-scales and the LYLES were moderate in general. The correlations between the LYLES and the SDQ-5 were somewhat weaker than the correlations with the SDQ-20.

The predictive value of the LYLES subscales on the SDQ-20 and the SDQ-5 was assessed by multiple regression analyses where the SDQ scores were regressed on the LYLES scores. The results are presented in Table 5.

Insert Table 5 about here 
The results in Table 5indicate that scores on the LYLES predicted the SDQ-20 somewhat better than the SDQ-5. This was the case particularly for the eating disorder group. It was striking that in the non-clinical group, non-interpersonal traumas had the lowest significance for dissociation, whereas this same subscale had the largest influence in the eating disorder group.

\section{Conclusions}

In this study, the psychometric characteristics of the Swedish versions of the SDQ-20 scale and its abbreviated version, the SDQ-5, have been analysed among adolescents and young adults, some in a non-clinical group and others in a clinical group of patients with an eating disorder. The analyses indicate that the SDQ-20 has acceptable internal consistency and adequate convergent validity in relation to the Dis-Q-Sweden, and moderate criterion-related validity to a questionnaire for potentially traumatic and adverse life experiences, the LYLES. Significant differences were found between the non-clinical and the clinical groups on both the SDQ-20 and the SDQ-5. The short form, the SDQ-5, had substantially lower internal consistency and correlated slightly less with the Dis-Q-Sweden.

Several studies have investigated somatoform dissociation in different patient samples $(7,16,17-21,48-50)$, but only a few have studied non-clinical samples $(23,35)$. The reported Cronbach's alpha in the literature seems to be higher in the clinical samples (6-7, 19-20), but lower in samples from the general population (23), as was also found in this study. 
The mean score on the SDQ-20 in the non-clinical sample in this study is very close to what Maaranen and co-workers (23) report from their study of a sample of the general population in Finland. Somatoform dissociative symptoms identified by the SDQ-20 seem to be very rare in the general population. In our analyses, we found significant gender differences in which the females reported higher somatoform dissociative symptoms on the SDQ-20 but not on the SDQ-5; we have found no other study reporting this gender difference on the SDQ-20. This is in contrast to Maaranen (23), who found a significant higher mean among males on the SDQ-20. On the other hand, there are few or no studies reporting on somatoform dissociation among adolescents, so this needs to be further investigated.

The mean score in the clinical group was above the cut-off that Nijenhuis has suggested. This shows that among clients with eating disorders, somatoform dissociative symptoms are not rare at all. The mean score in the clinical sample in this study was close to what has been found in some previous studies. For example, Müller-Pfeiffer (20) reported a mean score for women of 33.8 in a mixed clinical sample of dissociative disorder $(M=48.4, S D=15.3)$, PTSD $(M=35.0, S D=14.7)$, and anxiety disorders $(M=26.5, S D=11.6)$. A higher mean was reported in a Turkish study sample with Conversion Disorder patients where a mean of M $=50.6,(\mathrm{SD}=15.6)$ was found (48). Still another study (50) investigating somatoform dissociation in a clinical sample with depersonalisation disorder found only moderate elevation of the SDQ-20 score $(\mathrm{M}=28.5, \mathrm{SD}=7.6)$. It seems that somatoform dissociation varies among clinical groups, with higher scores among patients with either dissociative, conversion, or eating disorders. These findings need to be addressed in future studies in different clinical groups and diagnoses. 
The correlations between the Dis-Q-Sweden and the SDQ-20 were significant for the whole scale as well as for the subscales. However, the correlations were lower than what has been found in clinical groups $(6-7,19-20)$. It should be noted that in the study by MüellerPfeiffer (20), the German version of the Dissociative Experience Scale (DES) was used (15), which could make a difference. On the other hand, the study by Maaranen (23) with a nonclinical sample found correlations between the SDQ-20 and the DES that were similar to what was found in this study.

The correlations between somatoform dissociation and the LYLES trauma checklist were moderate overall (51). Several other studies have also found a modest link between trauma and dissociative symptoms. Factors such as, cognitive failures, fantasy proneness, affect regulation, and attachment style could influence and moderate the link between trauma and dissociation (52-57). The finding that the influence of non-interpersonal traumas had the largest influence on dissociation was unexpected. One interpretation could be that there might be a possible linkage to difficulties in affect regulation found in other eating disorder patients (36-37).

In this study, adverse childhood circumstances were associated more with somatoform dissociation than specific traumas. This has been found in other studies as well $(22,49)$.

SDQ-5 was not measured separately, but as a part of the SDQ-20. This might have influenced the responses on the five questions. The results in this study can be compared to results in a previous study also conducted in Sweden in a sample of adolescents (47) where the SDQ-5 was distributed separately. In that study, similar results as in the present study were obtained for Cronbach'alpha ( $\alpha=.47$ versus $\alpha=.50$ in this study) and for mean values 
$(\mathrm{M}=5.64(\mathrm{SD}=1.47)$ versus $\mathrm{M}=5.7(\mathrm{SD}=1.4)$. However, halo effects from the common distribution could not be excluded (57).

In future studies and in clinical practice, it may be meaningful to search for common factors in the SDQ-20, the Dis-Q, or the DES by following the model in the newly developed Interview for Dissociative Disorders and Trauma-related Symptoms (56). It could be valuable to have one screening instrument that identifies both psychoform and somatoform dissociation symptoms and behaviours. It might then also be valuable to further investigate the dimensions of the instruments with for instance factor analyses.

The main conclusion of this study is that the psychometric characteristics of the SDQ20 concerning adolescents were acceptable while those of the SDQ-5 were weaker; considering that the SDQ-20 is a rather short questionnaire itself, the need for a shorter version (SDQ-5) with poorer psychometric properties is not supported by this study.

\section{References}

1 Putnam F.W. Dissociative disorders in children: behavioural profiles and problems. Child Abuse and Neglect 1993; 17: 39-45. 
2 Dell, P. F., O’Neil, J, A. Ed.s Dissociation and Dissociative Disorders, DSM-V and beyond. New York Routledge Taylor \& Francis Group New York; 2009.

3 Steinberg M. Structured clinical interview for DSM-IV dissociative disorder (SCIDD), revised. Washington, DC: American Psychiatric Press;1994.

4 Maldonado JR, Spiegel D. Trauma, dissociation, and hypnotizability. In Bremner JD, Marmar CR, editors. Trauma, memory, dissociation. Washington, D: American Psychiatric Press 1998; 57-106.

5 Nijenhuis ERS. Somatoform dissociation: Phenomena, measurement, and theoretical issues. New York NY: Norton; 2004.

6 Van der Hart O, Van Dijke A, Van Son M, Steele K. Somatoform dissociation in traumatized World War I combat soldiers: A neglected clinical heritage. J Trauma \& Dissociation 2000; 1:33-66.

7 Nijenhuis, ERS., Spinhoven, P., van Dyck, R. van der Hart, O., Vanderlinden, J. The development and psychometric properties of the somatoform dissociation questionnaire (SDQ-20). J Nervous and Mental Disease 1996; 184: 688-694.

8 Nijenhuis ERS, Spinhoven P, van Dyck R, van der Hart O, Vanderlinden J. Psychometric Characteristics of the Somatoform Dissociation Questionnaire: A Replication Study. Psychotherapy and Psychosomatics 1998; 67:17-23.

9 Kozlowska K, Nunn KP, Rose D, Morris A, Ouvrier RA, Varghese J. Conversion disorder in Australian pediatric practice. J Am Acad Child and Adolescent Psychiatry 2007; 46: 68-75. DOI:10.1097/01.chi.0000242235.831.1f 
10 Sar V, Islam S, Öztürk E. Childhood emotional abuse and dissociation in patients with conversion symptoms. Psychiatry and Clinical Neurosciences 2009; 63:670677.doi:10.1111/j.1440-1819.2009.02012.x

11 Bob P, Selesova P, Raboch J, Kukla L. 'Pseudoneurological' symptoms, dissociation and stress-related psychopathology in healthy young adults. BMC Psychiatry 2013;13: 149 Http:/www.biomedcental.com/1471-244X/13/149

12 World Health Organization. International Classification of Diseases, $10^{\text {th }}$ edn. (ICD10). World Health Organization, Geneva, 1992.

13 American psychiatric Association. Diagnostic and statistical manual of Mental Disorders, $4^{\text {th }}$ edn. American Psychiatric Association, Washington, DC, 1994.

14 American psychiatric Association. Diagnostic and statistical manual of Mental Disorders, $5^{\text {th }}$ edn. American Psychiatric Association, Washington, DC, 2013

15 Bernstein E, Putnam, FW. Development, reliability, and validity of a dissociation scale. J Nervous and Mental Disease 1986; 102: 280-286.

16 Vanderlinden J. Dissociative experiences, trauma and hypnosis: Research findings and clinical applications in eating disorders. Delft: Eubron 1993.

17 Sar V, Kundakci T, Kiziltan E, Bakim B, Bozkurt O. Differentiating dissociative disorders from diagnostic groups through somatoform dissociation in Turkey. J Trauma \& Dissociation 2000; 4: 67-80.

18 El-Hage W, Darves-Bornoz J-M, Allilaire J-F, Gaillard P. Post traumatic somatoform dissociation in French psychiatric outpatients. Journal of Trauma and Dissociation 2002; 3: 59-73. 
19 Espirito Santo H M A, Pio-Abreu J L. Dissociative disorders and other psychopathological groups: exploring the differences trough the Somatoform Dissociation Questionnaire (SDQ-20). Revista Brasileria de Psiqiatria 2007; 29, 3:54358.

20 Mueller-Pfeiffer C, Schumacher S, Martin-Soelch C, Pazhenkottil AP, Wirtz G, Fuhrhans C, et al. The validity and reliability of the German version of the Somatoform Dissociation Questionnaire (SDQ-20). J Trauma \& Dissociation 2010; 11: 337-357.

21 Nijenhuis ERS, Spinhoven P, van Dyck R, van der Hart O, Vanderlinden J. The development of the somatoform dissociation questionnaire (SDQ-5) as a screening instrument for dissociative disorders. Acta Psychiatria Scandinavia 1997; 96: 311318.

22 Brunner R, Prazer P, Schuld V, Resch F .Dissociative symptomatology and traumatogenic factors in adolescent psychiatric patients. J Nervous and Mental Disease 2000; 188: 71-77.

23 Maaranen P, Tanskanen A, Haatainen K, Koivurmaa-Honkanen H, Hintikka J, Viianamäki H. Somatoformdissociation and adverse childhood experiences in the general population. J Nervous and Mental Disease 2004; 192:337-342.

24 Roelofs K, Keijsers GP, Hoogduin KA, Näring GP, Moene FC. Childhood abuse in patients with conversion disorder. Am J of Psychiatry 2002; 159 (11):1908-13.

25 Ross C A, Joshi S, Currie R. Dissociative experiences in the general population: A factor analysis. Hospital and Community Psychiatry 1991; 42: 297-301. 
26 Ross C A, Keyes B B, Xiao Z, Yan H, Wang Z, Zou Z, et al. A cross-cultural test of the trauma model of dissociation. J Trauma \& Dissociation 2008; 9: 35-39.

27 Ross CA, Ness L. Symptom patterns in dissociative identity disorder patients and the general population. J Trauma \& Dissociation 2010; 11, 4: 458-468.

28 Nilsson D, Svedin CG. Evaluation of the Swedish version of dissociation questionnaire (Dis-Q), Dis-Q-Sweden, among adolescents. J Trauma \& Dissociation 2006; 7:65-89.

29 Nilsson D, Svedin CG. Dissociation among Swedish adolescents and the connection to trauma. An evaluation of the Swedish version of Adolescent Dissociative Experience Scale. J Nervous and Mental Disease 2006; 194: 684- 689.

30 Svedin CG, Nilsson D, Lindell C. Traumatic experiences and dissociative symptoms among Swedish adolescents. A pilot study using Dis-Q-Sweden. Nordic J Psychiatry 2004; 58:349-355.

31 Nilsson D, Gustafsson P, Svedin C G. Self- reported potentially traumatic life events and symptoms of post- traumatic stress and dissociation. Nordic J Psychiatry 2010; 64: 19-26.

32 Nilsson D, Gustafsson P E, Larsson J, Svedin C G. Evaluation of Linköping Youth Life Experience Scale. J Nervous and Mental Disease 2010; 198: 768-774.

33 Friedrich WN, Gerber PN, Koplin B, Davis JG, Mykelbust C, Franckowiak F. Multimodal assessment of dissociation in adolescents: Inpatients and juvenile sex offenders. Sexual Abuse: Am J Research and Treatment 2001; 13: 167-177.

34 Ogawa, J .R., Sroufe, A. L., Weinfield,N S, Carlson, E.A., \& Egeland, B.(1997) Development and the fragmented self: Longitudinal study of dissociative 
symptomatology in a non-clinical sample. Development and Psychopathology 9: 855879.

35 Maaranen P, Tanskanen A, Haatainen K, Honkalampi K, Koivumaa H, Hintikka, J,et al. The relationship between psychological and somatoform dissociation in the general population. J Nervous and Mental Disease 2005; 193: 690-693.

36 Farrington A, Waller G, Neiderman M, Sutton V, Chopping J, Lask B. Dissociation in adolescent girls with anorexia: Relationship to comorbid psychopathology. J Nervous and Mental Disease 2002; 190: 746-751.

37 La Mela C, Maglietta M, Castellini G, Amoroso L, Lucarelli S. Dissociation in eating disorders: relationship between dissociative experiences and binge-eating episodes. Comprehensive Psychiatry 2010; 5: 393-400

38 Vanderlinden J, Vandereycken W. Trauma, dissociation, and impulse dyscontrol in eating disorders. Bristol: Brunner/Mazel, Publishers; 1997.

39 Gerke C, Mazzeo S, Kliewer W. The role of depression and dissociation in the relationship between childhood trauma and bulimic symptoms among ethnically diverse female undergraduates. Child Abuse \& Neglect 2006; 30: 1161-1172.

$40 \mathrm{McShane}$ J, Zirkel S. Dissociation in the binge-purge cycle of bulimia nervosa. J Trauma \& Dissociation 2008; 9: 463-479.

41 Nijenhuis ERS. The scoring and interpretation of the SDQ-20 and SDQ-5. Activitas Nervosa Superior 2010; 52: 24-28. 
42 Mercado R, Matinez-Taboas A, Pedrosa O. Childhood sexual abuse, eating disturbance and dissociation; A study in Puerto Rico. J Psychological Trauma 2008; 7:298-309

43 Nilsson D, Nordfelt S, Wadsby M. SDQ-20 and SDQ-5. Translation to Swedish. BUP - Elefanten 2006.

44 Häggström, M. SDQ-20 Sweden: validation of the Swedish version of the Somatoform Dissociation Questionnaire. Master thesis, 2007 Linköping University, Sweden.

45 Derogatis L R. SCL-90: Administration, scoring, and procedures manual-I for the Revised version and other instruments of the psychopathology rating scale series. Baltimore. Clinical Psychometric Research Unit, John Hopkins University School of Medicine 1977.

46 Simeon D, Smith RJ, Knutelska M, Smith LM. Somatoform dissociation in depersonalization disorder. J Trauma and dissociation 2008; 9: 335-348

47 Larsson J. Self-reported potentially traumatic life events and symptoms of dissociation, depression and anxietyamong adolescents. Reliability test of two new instruments. MA thesis 2008 Linköping University. 
48 Sar V, Akyüz G, Kundakci T, Kiziltan E., Dogan O. Childhood trauma, dissociation, and psychiatric comorbidity in patients with conversion disorder. Am J Psychiatry 2004;161:2271-6

49 Sar V, Serkan I, Esdinc Ö. Childhood emotional abuse and dissociation in patients with conversion symptoms. Psychiatry and Clinical Neurosciences 2009; 63: 670677.

50 Simeon,D, Smith RJ, Knutelska M, Smith LM. Somatoform dissociation in depersonalization disorder. J Trauma \& Dissociation; 9: 335-348. Doi: 10.1080/15299730802139170.

51 Cohen J. A power primer. Psychological Bulletin 1992; 112: 155-159.

52 Giesbrecht T,Lynn ST, Lilienfeld SO, Merckelbach H. Cognitive processes in dissociation: An analysis of core theoretical assumptions. Psychological Bullertin 2008; 5 617-647. DOI:10.1037/0033.2009.134.5617

53 Merckelbach H, Muris P. The causal link between self-reported trauma and dissociation: A critical review. J Behavioral Research Therapy 2001; 39:245-54. doi.org.lt.ltag.bibl.liu.se/10.1016/S0005-7967(99)00181-3 
54 Giesbrecht T, Merckelbach H. Über die kausale Beziehung zwischen Dissoziation und Trauma Ein kritischer Überblick. Nervenarzt 2005; 20-7 . DOI 10.1007/s00115004-1704-9.

55 Briere J. Is dissociation a multidimensional construct? Data from the Multiscale Dissociation Inventory. J Traumatic Stress 2005; 18:221-231.

56 Briere J. Dissociative symptoms and trauma exposure specificity, affect dysregulation, and posttraumatic stress. J Nervous and Mental Disease, 2006; 194, 2: 78- 82.

57 Nilsson D, Holmqvist R, Jonsson M. Self-reported attachment style, trauma exposure and dissociative symptoms among adolescents. Attachment and Human Development 2001; 579-595.

58 Nisbett RE, Wilson TD. The halo effect: Evidence for unconscious alteration of judgments. Journal of Personality and Social Psychology, 1977; 35, 250-256. Doi:10.1037/0022-3514:35.4.250

59 Boon S, Draijer N, Matthess H. Interview for Dissociative Disorders and Trauma-related Symptoms / IDDTS. 2007 
Table 1.

Separate scores for male and female in the non-clinical group $(N=455)$

\begin{tabular}{|c|c|c|c|c|c|c|c|c|}
\hline & \multicolumn{3}{|c|}{ Male $(n=213)$} & \multicolumn{2}{|c|}{ Female $(n=242)$} & \multirow[b]{2}{*}{ IQR } & \multirow{2}{*}{\multicolumn{2}{|c|}{$\begin{array}{c}\text { Mann-Whitney U test } \\
\text { significance }\end{array}$}} \\
\hline & $\mathrm{M}(\mathrm{SD})$ & Median & IQR & $\mathrm{M}(\mathrm{SD})$ & Median & & & \\
\hline SDQ-20 & $23.2(4.8)$ & 22 & 4 & $24.1(5.3)$ & 23 & 6 & & $<.01$ \\
\hline \multirow[t]{2}{*}{ SDQ-5 } & $5.7(1.4)$ & 5 & 1 & $5.8(1.4)$ & 5 & 1 & & $\mathrm{~ns}$ \\
\hline & & & & & & & $\mathrm{t}$ & significance \\
\hline DIS-Q total & $1.62(.42)$ & 1.51 & .54 & $1.91(.52)$ & 1.80 & .62 & 43.0 & $<.001$ \\
\hline Identity confusion & $1.38(.43)$ & 1.24 & .36 & $1.67(.61)$ & 1,48 & .64 & 34.5 & $<.001$ \\
\hline Loss of control & $1.71(.52)$ & 1.64 & .55 & $2.13(.65)$ & 2.00 & .83 & 57.7 & $<.001$ \\
\hline Amnesia & $1.54(.45)$ & 1.43 & .50 & $1.71(.55)$ & 1.59 & .59 & 14.1 & $<.001$ \\
\hline Absorption & $1.85(.67)$ & 1.67 & 1.00 & $2.13(.69)$ & 2.17 & 1.04 & 19.2 & $<.001$ \\
\hline \multicolumn{9}{|l|}{ LYLES } \\
\hline Interpersonal traumas & $.17(.14)$ & .15 & .23 & $.15(.14)$ & .15 & .15 & .16 & $\mathrm{~ns}$ \\
\hline Non-interpersonal traumas & $.45(.21)$ & 44 & .28 & $.39(.18)$ & .15 & .22 & 4.23 & $<.05$ \\
\hline Adverse childhood circumstances & $.13(.15)$ & .10 & .10 & $.17(.17)$ & .10 & .30 & 8.06 & $<.01$ \\
\hline
\end{tabular}

$S D Q-20=$ Somatoform dissociation questionnaire $-20, S D Q-5=$ Somatoform dissociation questionnaire -5 ,

LYLES = Linkoping Youth Life Experience Scale, Dis-Q-Sweden-Dissociation Questionnaire Sweden. 
Table 2.

Comparisons between the non-clinical $(n=455)$ and the clinical $(n=50)$ groups and between only non-clinical females $n=242$ and the clinical group for the scales SDQ-20, SDQ-5, Dis-Q-Sweden and LYLES.

\begin{tabular}{|c|c|c|c|c|c|c|}
\hline \multirow[t]{2}{*}{ Scales } & \multirow{2}{*}{$\begin{array}{l}\text { Non-clinical } \\
\text { Group } \\
\text { Median (range) }\end{array}$} & \multirow{2}{*}{$\begin{array}{l}\text { Patients with } \\
\text { eating disorders } \\
\text { Median (range) }\end{array}$} & \multicolumn{2}{|c|}{$\begin{array}{l}\text { Comparison between all } \\
\text { participants }\end{array}$} & \multicolumn{2}{|c|}{$\begin{array}{l}\text { Comparison between } \\
\text { female participants }\end{array}$} \\
\hline & & & Mann & $\begin{array}{r}\text { Whitney } U \text { - test } \\
\text { significance }\end{array}$ & Mann - И & $\begin{array}{l}U \text {-test } \\
\text { significance }\end{array}$ \\
\hline SDQ-20 & $22(17-67)$ & $29(20-63)$ & & $<.001$ & & $<.001$ \\
\hline SDQ-5 & $5(3-17)$ & $7(5-18)$ & & $<.001$ & & $<.001$ \\
\hline & $M(S D)$ & $M(S D)$ & $t$ & significance & $t$ & significance \\
\hline DIS-Q total & $1.77(.50)$ & $2.64(.67)$ & 125.4 & $<.001$ & 72.0 & $<.001$ \\
\hline Identity confusion & $1.52(.56)$ & $2.85(.88)$ & 221.0 & $<.001$ & 130.1 & $<.001$ \\
\hline Loss of control & $1.94(.63)$ & $2.80(.87)$ & 78.1 & $<.001$ & 38.4 & $<.001$ \\
\hline Amnesia & $1.63(.51)$ & $1.99(.65)$ & 20.4 & $<.001$ & 9.6 & $<.01$ \\
\hline Absorption & $2.00(.69)$ & $2.91(.80)$ & 75.7 & $<.001$ & 50.3 & $<.001$ \\
\hline LYLES & & & & & & \\
\hline Interpersonal traumas & $.16(.14)$ & $.14(.15)$ & 1.1 & ns & .95 & ns \\
\hline Non-interpersonal traumas & $.40(.18)$ & $.31(.18)$ & 11.8 & $<.01$ & 5.6 & $<.05$ \\
\hline Adverse childhood circumstances & $.15(.16)$ & $.26(.17)$ & 19.3 & $<.001$ & 10.4 & $<.001$ \\
\hline
\end{tabular}

SDQ-20=Somatoform dissociation questionnaire -20, SDQ-5=Somatoform dissociation questionnaire -5,

LYLES = Linkoping Youth Life Experience Scale, Dis-Q-Sweden-Dissociation Questionnaire Sweden. 
Table 3.

Correlations between $S D Q-20$ and $S D Q-5$ (both log transformed) and Dis-Q-Sweden.

\begin{tabular}{|c|c|c|c|c|c|}
\hline & \multicolumn{5}{|c|}{ Dis-Q } \\
\hline & $\begin{array}{l}\text { Identity } \\
\text { confusion }\end{array}$ & $\begin{array}{l}\text { Loss of } \\
\text { control }\end{array}$ & Amnesia & Absorption & Dis-Q total \\
\hline \multicolumn{6}{|c|}{ Clinical group $(n=50)$} \\
\hline SDQ-20 & $.52 * * *$ & $.34 *$ & $.62 * * *$ & $.58 * * *$ & $.60 * * *$ \\
\hline SDQ-5 & $.49 * * *$ & $.42 * *$ & $.41 * *$ & $.41^{* *}$ & $.52 * * *$ \\
\hline \multicolumn{6}{|c|}{ Non-clinical group $(n=455)$} \\
\hline SDQ-20 & $.55 * * *$ & $.50 * * *$ & $.60 * * *$ & $.31 * * *$ & $.58 * * *$ \\
\hline SDQ-5 & $.42 * * *$ & $.33 * * *$ & $.44 * * *$ & $.20 * * *$ & $.40^{* * *}$ \\
\hline \multicolumn{6}{|c|}{ All participants $(N=505)$} \\
\hline SDQ-20 & $.62 * * *$ & $.54 * * *$ & $.62 * * *$ & $.43^{* * *}$ & $.64 * * *$ \\
\hline SDQ-5 & $.50 * * *$ & $.41 * * *$ & $.46^{* * *}$ & $.31 * * *$ & $.49 * * *$ \\
\hline
\end{tabular}

$* \mathrm{p}<.05, * * \mathrm{p}<.01, * * * \mathrm{p}<.001, S D Q-20=$ Somatoform dissociation questionnaire $-20, S D Q-5=$ Somatoform dissociation questionnaire, Dis-Q-Sweden-Dissociation Questionnaire Sweden. 
Table 4.

Correlations between the SDQ-20,SDQ-5 and LYLES

\begin{tabular}{|c|c|c|c|}
\hline & $\begin{array}{l}\text { Interpersonal } \\
\text { traumas }\end{array}$ & \begin{tabular}{l}
\multicolumn{1}{c}{ LYLES } \\
Non-interpersonal \\
traumas
\end{tabular} & $\begin{array}{l}\text { Adverse Childhood } \\
\text { Circumstances }\end{array}$ \\
\hline \multicolumn{4}{|c|}{ Clinical group $(N=50)$} \\
\hline SDQ-20 & .25 & $.38 * *$ & $.33^{*}$ \\
\hline SDQ-5 & $.30 *$ & .27 & .20 \\
\hline \multicolumn{4}{|c|}{ Non-clinical group $(N=455)$} \\
\hline SDQ-20 & $.23 * * *$ & $.20 * * *$ & $.18^{* * *}$ \\
\hline SDQ-5 & $.15^{* *}$ & $.19 * * *$ & $.20 * * *$ \\
\hline \multicolumn{4}{|c|}{ All participants $(\mathrm{N}=505)$} \\
\hline SDQ-20 & $.24 * * *$ & $.17 * * *$ & $.25^{* * *}$ \\
\hline SDQ-5 & $.25 * * *$ & $.25 * * *$ & $.24 * * *$ \\
\hline
\end{tabular}


Table 5.

Results of a multiple regressions analysis with the scores on SDQ-20 and SDQ-5

(using log transformed scores) regressed on the subscales in LYLES.

\begin{tabular}{|c|c|c|c|c|c|c|}
\hline \multirow[t]{2}{*}{ LYLES } & \multicolumn{3}{|c|}{ SDQ-20 } & \multicolumn{3}{|c|}{ SDQ-5 } \\
\hline & $\begin{array}{l}\text { Adjusted } \\
\text { R2 for } \\
\text { model }\end{array}$ & $\begin{array}{c}\text { Model } \\
\text { significance/standardized } \\
\text { coefficient significance } \\
\text { F (p) }\end{array}$ & Beta & $\begin{array}{l}\text { Adjusted } \\
\text { R2 for } \\
\text { model }\end{array}$ & $\begin{array}{c}\text { Model } \\
\text { significance/standardized } \\
\text { coefficient significance } \\
\text { F (p) }\end{array}$ & Beta \\
\hline$\frac{\text { Non-clinical }}{\text { group* }}$ & .071 & $11.24(<.001)$ & & .062 & $9.91(<.001)$ & \\
\hline $\begin{array}{l}\text { Non- } \\
\text { interpersonal } \\
\text { traumas }\end{array}$ & & $2.03(.04)$ & .10 & & $1.64(.10)$ & .08 \\
\hline $\begin{array}{l}\text { Interpersonal } \\
\text { traumas }\end{array}$ & & $2.68(.008)$ & .14 & & $1.69(.09)$ & .09 \\
\hline $\begin{array}{l}\text { Adverse } \\
\text { childhood } \\
\text { circumstances }\end{array}$ & & $2.24(.03)$ & .11 & & $3.24(.001)$ & .16 \\
\hline$\frac{\text { Eating } * *}{\text { disorder group }}$ & .223 & $4.40(.008)$ & & .116 & $2.00(.13)$ & \\
\hline $\begin{array}{l}\text { Non- } \\
\text { interpersonal } \\
\text { traumas }\end{array}$ & & $2.29(.03)$ & .36 & & $1.38(.18)$ & .23 \\
\hline $\begin{array}{l}\text { Interpersonal } \\
\text { traumas }\end{array}$ & & $.71(.48)$ & .11 & & $1.05(.30)$ & .17 \\
\hline $\begin{array}{l}\text { Adverse } \\
\text { childhood } \\
\text { circumstances }\end{array}$ & & $.55(.59)$ & .09 & & $.01(.99)$ & .002 \\
\hline
\end{tabular}

